perteneciente a la asociación Ulici gallii-Ericetum mackaiance Dalda 1972. Hay que resaltar la baja altitud del lugar del hallazgo para un taxon que en la Península Ibérica se restringe a áreas de alta montaña de los Sistemas Pirenaico-cantábrico, Ibérico y Central (cf. L. Villar, Huperzia Bernh. In S. Castroviejo \& al. (Eds.) Flora Ibérica, 1:5. 1986), aunque el reciente descubrimiento en la misma zona de amplias poblaciones de la orófila Gentiana verna L. ( J. Rodríguez-Oubiña \& P. Guitian, Anales Jard. Bot. Madrid, en prensa) ya suponía la posibilidad de este tipo de recolecciones.

De Galicia únicamente se conocía una reciente herborización de J. Reinoso \& J. Rodríguez-Oubiña (Acta Bot. Malacitana, 12:254. 1987) en la Sierra de Ancares (Cervantes, Lugo) y la inicial, de Merino, en Galdo (Viveiro, Lugo) que, probablemente por su baja altitud, no fue reflejada en el APIB.

Equisetum ramosissimum Desf.

A CORUÑA: Valdoviño, 29TNJ6829, 10.VI.84, en las riberas del río Magno, cerca de la playa de A Frouxeira.

Las escasas citas gallegas de este equiseto corresponden a las otras tres provincias.

Hymenophyllum tumbrigense (L.) Sm.

A CORUÑA: Narahío (San Sadurniño), 29TNJ7416, 22.II.84, 100 m s.n.m., en un bosque de la cuenca del río Cando.

Nueva localidad gallega que añadir a la clásica de la Fraga de Caaveiro (A Capela) y a la recientemente descubierta de la cuenca del río Mandeo (Coirós) (J. Cremades \& I. Ibarra, Acta Bot. Malacitana, 12:252. 1987), ambas en la misma provincia.

\title{
20. Aportación al Catálogo Pteridoflorístico de la provincia de Málaga
}

J.M. NIETO, A.V. PEREZ-LATORRE, B. CABEZUDO, J.R. BOYERO, A.M. ESCAMEZ \& A.E. SALVO Departamento de Biología Vegetal Universidad de Málaga

Las recolecciones pteridológicas realizadas en los últimos años en la provincia de Málaga han dado como resultado un importante número de nuevas citas que, en base a Salvo (1982), amplian el areal de varios taxones. Tales citas serán oportunamente publicadas en una sintesis próxima pero, en todo caso, deseamos poner de manifiesto en esta nota aquéllas cuyo valor corológico es destacable.

1. Polypodium interjectum Shivas.

MALAGA: Serranía de Ronda, Igualeja, El Robledal (UF 1656), 1250 m.s.m., 17-VII-1987, Pérez-Latorre (MGC).

En una grieta sobre gneises duros, compartiendo dicho albergue con Asplenium billotii Schultz. 
2. Asplenium scolopendrium L.

MALAGA: Mollina, Sierra de Mollina, (UF 51), 700 m.s.m., 15-XI-1987. Nieto \& Bollero. (MGC 22702).

Se ubica en el umbral de una caverna, como terrícola, sobre arcillas descalcificadas, limitando su desarrollo el factor lumínico.

3. Athyrium filix-femina (L.) Roth.

MALAGA: Serranía de Ronda, Igualeja, La Fuentefría, (UF 1657), 1250 m.s.m., 27-VII-1987, Pérez-Latorre (MGC).

La presencia de este taxon en el sector rondeño resulta anómala por cuanto los requerimientos ecológicos del mismo hacen que su aparición se encuentre limitada. La única población encontrada está constituída por escasos indivíduos que viven cobijados en un pequeño arroyo junto a Pteridium aquilinum (L.) Kuhn, dominando Pinus pinaster Aiton la cobertura arbórea de la zona.

MALAGA: Casares, Majada-Madrid, (TF 9840), 20-V-1988, Cabezudo \& Pérez-Latorre, (MGC).

Al igual que la anterior localidad, ésta pertenece también al sector rondeño. Es evidente que la proximidad del sector aljíbico hace que la influencia de elementos atlánticos en esta localidad sea muy alta, entre otros, además de A. filix femina, Davallia canariensis (L.) Sm., Dryopteris affinis (Lowe) Fraser-Jenkins y Polystichum setiferum (Forsskal) Woynar.

4. Polystichum setiferum (Forsskal) Woynar

MALAGA: Antequera, Sierra del Torcal, Pilón del Agracejo, (UF 69), 11-II-1985, J. Carreira (MGC 16526).

Aunque esta cita ya fue recogida por Salvo \& cols. (1986) queremos volver a destacarla tanto por su situación biogeográfica como ecológica, puesto que $P$. setiferum en esta localidad se comporta de forma bastante desviante respecto a su óptimo ecológico, por cuanto el único ejemplar encontrado aparece colonizando una grieta profunda y resguardada.

MALAGA: Casares, Majada-Madrid, ( TF 9840), 20-V-1988, Cabezudo \& PérezLatorre (MGC).

Convive con la especie anterior a lo largo de un arroyo, sobre sustratos esquistosos donde Quercus canariensis Willd. domina la vegetación arbórea. La única población está constituída por escasos indivíduos aislados.

5. Dryopteris affinis (Lowe) Fraser-jenkins subsp. affinis

MALAGA: Casares, Majada-Madrid, (TF 9840), 20-V-1988, Cabezudo \& PérezLatorre. (MGC).

D. affinis es una especie rara en Andalucía. La subespecie affinis se relega a la Sierra de Aracena, Salvo (1982) y según Fraser-Jenkins (1982) también a Sierra Nevada donde conviviría con la subespecie borreri (Newman) Fraser-Jenkins en la misma localidad. Fraser-Jenkins (op. cit.)recoge varias citas bibliográficas de esta subespecie para las Sierras de Algeciras sin que hayan podido ser confirmadas. Nuestra cita pues, corresponde a la más meridional de la Peninsula Ibérica. Como ya se ha mencionado esta especie convive con P. setiferum y A. filix-femina en el cauce de un arroyo umbrío y profundo.

6. Davallia canariensis (L.) Sm.

MALAGA: Casares, Majada-Madrid, ( TF 9840, TF 9641), 20-V-1988, Cabezudo \& Pérez-Latorre. (MGC).

Vive epífito junto a Polypodium cambricum L. sobre las horquillas de Quercus canariensis Willd.

Este trabajo ha sido realizado con cargo al proyecto CAYCIT. PA 85-0344/86. 


\section{B IBL IOGR AF IA}

FRASER-JENKINS, C.R. -1982- Dryopteris in Spain, Portugal and Macaronesia. Bol. Soc. Brot. Sér. 2, 55:175-336.

SALVO, A.E. -1982- Flora Peridofítica de Andalucía. Málaga.

SALVO, A.E., HIDALGO, M.I., ROSELLO, J.A. \& PERICAS, J. -1986- Estudio biosistemático del género Polystichum Roth (Aspidiaceae, Pteridophyta) en la Península Ibérica. Bol. Soc. Brot. Sér. 2, 59:113-165. 